\title{
Measuring inflation through stochastic approach to index numbers
}

\author{
Zahid Asghar \\ Quaid-i-Azam University \\ Islamabad, Pakistan \\ g.zahid@gmail.com \\ Farhat Tahira \\ Quaid-i-Azam University \\ Islamabad, Pakistan
}

\begin{abstract}
This study attempts to estimate the rate of inflation in Pakistan by the stochastic approach to index numbers by allowing systematic changes in relative prices. This approach provides not only point estimate but also confidence interval for the rate of inflation. There are two types of approaches to index number theory namely: the functional economic approaches and the stochastic approach. The attraction of stochastic approach is that it estimates the rate of inflation in which uncertainty and statistical ideas play a major roll of screening index numbers We use CPI data covering the period July 2001--March 2008 for Pakistan and find that if prices of individual commodities are widely dispersed then the level of uncertainty for measuring the rate of inflation will be very high. We find that the rate of inflation was changing significantly from month to month and by applying stochastic approach to index numbers we gained some level of confidence that our estimated range will contain the true parameter of the rate of inflation.
\end{abstract}

\section{Introduction}

Inflation is a rise in the price and wages caused by an increase in the money supply and demand for goods, resulting in a fall in the value of money. Wilson (1982) said "inflation is a sharp increase in the rate of change of some price index above a previous normal level." Inflation is measured by using CPI because CPI is directly related to people's purchasing power of fixed basket of goods and services. When inflation rises, people can buy only small number of things and vice versa. Inflation is used in negotiating wages, providing social security benefits, reviewing contracts etc. This requires inflation to be measured by using the best statistical techniques.

The objective of this study is to estimate the rate of inflation for Pakistan. So far the Laspeyres index based on fixed basket approach to index numbers is used to estimate the rate of inflation for Pakistan. In this study we used the stochastic approach to index numbers to estimate the rate of inflation.

To estimate the rate of inflation there are two main approaches namely functional approach to index numbers of Diewert (1981), Balk (1995) which dates back to Fisher (1922), and the second is stochastic approach to index numbers theory reintroduced by Frisch (1936), Theil (1975), Clements and Izan (1981), Clements and Izan (1987), Selvanathan (1989), Diewert (1995), Crompton (2000), Selvanathan (2003), Selvanathan and Selvanathan (2003), Selvanathan and 
Selvanathan (2004), Selvanathan and Selvanathan (2006), Clements et. al (2006), Clements and Selvanathan (2007).

The information required to apply stochastic approach to index numbers is prices of $n$ commodities in two time periods say $t$ and $t-1$. According to Clements and Izan (1985), the difference between the prices of the period's $t$ and $t-1$ contains two portions one is trend component (rate of inflation) and the other is random component. Selvanathan and Selvanathan (2006) said that the sum of price change would contain only the pure trend component because summing will remove the random component. So the average change of the prices gives the rate of inflation. Following are the advantages to use stochastic approach to index numbers for the estimation of rate of inflation.

Firstly, like other traditional approaches stochastic approach to index numbers provides point estimate of inflation. It has been found that the estimate through this stochastic approach is approximately close to that of official estimate. Secondly, the stochastic approach to index numbers provides the whole distribution of the rate of inflation. Stochastic approach gives standard error for the rate of inflation where as other approaches only are based on point estimates of the rate of inflation. The standard errors obtained can be used to get an idea about the uncertainty level in the rate of inflation. The main attraction of the stochastic approach over other approaches is that it could be used to express the inflation target in a range. We have some level of confidence that estimated range will contain the true inflation but in point estimation we are not sure whether our estimate will approach to true inflation or not. According to Casella and Berger (2002) though we loss some precision in estimating confidence interval but at the same time we gain some confidence coefficient about the parameter. The advantage of the confidence interval is "The purpose of using an interval estimator rather than a point estimator is to have some guarantee of capturing the parameter of interest."Casella and Berger (2002) Thirdly, according to Clements and Izan (1987) the stochastic approach to index numbers is closely related to least square theory. All the estimators which are used in the stochastic approach to index numbers are derived by least square method. The merit of these estimators, derived through this link is that they will adopt the properties of the least square theory.

The weighted stochastic approach to index numbers, an extension of the simple stochastic approach to index numbers gives weights to all the commodities according to their importance in consumer's budget and hence it use weighted average for the point estimation.

Clements and Izan (1987) extended the stochastic approach to index number by allowing systematic changes in prices of commodities. He introduced a commodity specific component in the model. He found that results were not significantly different after allowing systematic changes in the commodities. Selvanathan (1989) extended the approach by allowing within group changes. His results were unbiased for the parameters as was proved with simulation. 
Clements and Izan (1987) imposed an assumption on the variance of errors that when commodities have larger budget shares then the variance will be smaller but when commodities had smaller budget shares then the commodities had larger variation. He derived estimators for this particular type of heteroscedasticity. So results will only be unbiased when such type of heteroscedasticity does not exists in the data. To overcome this problem Crompton (2000) formulated a generalized estimator of variance which did not concern with any type of heteroscedasticity and provided unbiased results.

Selvanathan (2003) noted that the Crompton's approach makes a reasonable reduction in variance than that of Clements and Izan (1987). After correction, it was seen that $75 \%$ values of standard error with Crompton's approach were smaller than that of Clements and Izan(1987) approach. Selvanathan and Selvanathan (2003) also wrote a book on international consumption comparisons. He used the data of OECD and LD (Least Developing) countries

and applied the stochastic approach to index numbers. Selvanathan and Selvanathan (2004) estimated the rate of inflation through stochastic approach to index numbers using the data for 23 OECD countries. Clements and Selvanathan (2007) stochastic index numbers was equivalent to the familiar optimal combination of forecasts with the individual prices playing the role of $n$ forecasts of the overall rate of inflation. This leads to new analytical results on the impact of adding additional information within the stochastic approach framework.

Rest of the paper is organized as follows. Section 2 is about methodologies of stochastic approach to index numbers in its extended version. Then it is used to match with Divisia index. It is also used to calculate Laspeyres index. Section 3 gives the empirical study of the approach for Pakistan and finally we concluded.

\section{Methodology}

\subsection{Extended Stochastic Approach to Index Number Theory by Allowing Systematic Changes in the Relative Prices}

Consider the model with an additional term to allow the some sustained change in the relative prices of commodities.

$$
D p_{i t}=\alpha_{t}+\beta_{i}+\mu_{i t} \text { Where } \mathrm{i}=1,2, \ldots, \mathrm{n} \text { and } \mathrm{t}=1,2, \ldots, \mathrm{T}
$$

Where $\alpha_{t}$ denotes the trend in the prices and $\beta_{i}$ denotes the part of change in the prices of individual commodities which is not random. The error term $\mu_{i t}$ is assumed to be random error, so its expected value is zero and independent both over time and across commodities which implies $\operatorname{cov}\left(\mu_{i t}, \mu_{j s}\right)=0$ where $\mathrm{i} \neq \mathrm{j}$ and $\mathrm{t} \neq \mathrm{s}$. Let $w_{i t}$ denote the budget share of $\mathrm{i}^{\text {th }}$ commodity at time $\mathrm{t}$. Also assume that the variance of this error is not stable over time and commodities; some form of heteroscedasticity is present in the model, the variance of errors is assumed to 
decrease as the commodity becomes more important in the consumers budget and vice versa

$$
\operatorname{var}\left(\mu_{i t}\right)=\frac{v_{t}^{2}}{\overline{w_{i t}}}
$$

The data are pooled both against time and across commodity. Let us first slightly relax the assumption in Eq.(2.2) and assume that it is only commodity dependent and not that of time. And after the first round of derivation we shall again assume its time dependence:

$$
\operatorname{var}\left(\mu_{i t}\right)=\frac{v^{2}}{\overline{w_{i}}}
$$

Since it varies only with commodities where $\overline{w_{i}}$ arithmetic averages of are $\overline{w_{i t}}$. Practically, the difference between $\overline{w_{i}}$ and $\overline{w_{i t}}$ is of no importance as budget shares tend to change slowly over time so we can write $\overline{w_{i}} \approx \overline{w_{i t}}$. Another issue with Eq.(2.1) is that it is under identified. Hence to overcome this problem, Clements and Izan (1987) impose the constrained $\sum_{i=1}^{n} \bar{w}_{i} \beta_{i}=0$ which is budget share weighted average of the systematic part of the changes in relative prices. By using GLS to the model Eq.(2.1) under Eq.(2.3), the BLUE of $\alpha_{t} \& \beta_{i}$ are

$$
\hat{\alpha}_{t}=\sum_{i=1}^{n} \overline{w_{i}} D p_{i t}, \hat{\beta}_{i}=\frac{\sum_{t=1}^{T}\left(D p_{i t}-\alpha_{t}\right)}{T}
$$

The above estimators are derived by replacing Eq. (2.2) with Eq. (2.3) which varies only with respect to commodities and not over time. Now let us find estimators by assuming variance is time dependent and replace $\bar{w}_{i t}$ with $\bar{w}_{i}$. By substituting Eq. (2.17) in (2.14), SSR is

$$
\delta_{t}^{2}=\sum_{i=1}^{n} \bar{w}_{i}\left(D p_{i t}-\tilde{\alpha}_{t}\right)^{2}+\sum_{i=1}^{n} \bar{w}_{i}\left(D \bar{p}_{i}-\overline{\tilde{\alpha}}\right)^{2}-2 \sum_{i=1}^{n} \bar{w}_{i}\left(D p_{i t}-\tilde{\alpha}_{t}\right)\left(D \bar{p}_{i}-\overline{\tilde{\alpha}}\right), \sum_{i=1}^{n} \zeta_{i t}{ }^{2}=\delta_{t}{ }^{2}
$$

On the right hand side of Eq.(2.5), the very first term is similar to the $2^{\text {nd }}$ order weighted moment about the mean of Divisia index. The only difference is that in Divisia index weights $\overline{w_{i t}}$ are used while here in stochastic approach we use its average $\overline{w_{i}}$. The second term measures the variation which comes in relative price of commodities on average but is not independent of time. When trend in price change is small and other components (errors) become large then inflation measurement will be poor. The third term (covariance) on the right hand side of Eq. (2.5) is positive when on average the relative prices of those goods that 
increase during $\mathrm{t}^{\text {th }}$ time also increase and vice versa. The GLS estimators of $\alpha_{t} \&$ $\beta$ after substituting (2.4) in (2.1) are

$$
\widehat{\alpha}_{t}=\sum_{i=1}^{n} \overline{w_{i}} D p_{i t}, \widehat{\beta}_{i}=\frac{\sum_{t=1}^{T} \frac{\left(D p_{i t}-\alpha_{t}\right)}{\delta_{t}^{2}}}{\sum_{t=1}^{T} \frac{1}{\delta_{t}^{2}}}
$$

As can be seen, the estimator $\tilde{\alpha}_{t}$ of the rate of inflation is identical to that estimated previously, the reason is that the new weighting factor $\frac{1}{\delta_{t}^{2}}$ is the same for all commodities with in the period $t$ and we measure inflation during $t$ by using only $\bar{w}_{1} w_{2} \ldots \bar{w}_{n}$ and $D p_{1 t}, D p_{2 t} \ldots D p_{n t}$ the estimator $\tilde{\beta}$ of the systematic component of the $\mathrm{i}^{\text {th }}$ relative price change is now a weighted average of this price change over all t periods. In contrast, $\hat{\beta}$ defined in Eq. (2.17), is an unweighted average. The weights in new approach $\varphi_{1}, \varphi_{2}, \ldots \varphi_{T}$ are inversely proportional to $\delta_{t}{ }^{2}$ which in turn is proportional to the error variance in time period t; thus smaller weights are allocated to those observations which have higher variance.

Clements (1987) variance estimator of the rate of inflation is given below

$$
\operatorname{var}\left(\widehat{\alpha}_{t}\right)=\frac{\delta_{t}^{2}}{n-1} \text { or } \operatorname{var}\left(\overline{\bar{\alpha}}_{t}\right)=\frac{1}{T^{2}} \sum_{t=1}^{T} \operatorname{var}\left(\widehat{\alpha}_{t}\right)
$$

The corresponding Crompton (2000) variance estimator is

$$
\operatorname{Var}\left(\widehat{\alpha}_{t}\right)=\sum_{i=1}^{n} \bar{w}_{i} \bar{\zeta}_{i t}^{2}
$$

This is weighted average of the squared random residuals. If the rate of inflation is constant then the Eq. (2.7) or Eq. (2.8) gives zero answer.

Clements (1987) variance estimator of systematic changes which occur in the relative prices is

$$
\operatorname{Var}\left(\widehat{\beta}_{t}\right)=\frac{i}{n-1} \sum_{t=1}^{T} \frac{1}{\delta_{t}^{2}}\left(\frac{1}{w_{i}}-1\right)
$$

This variance gets increased as the commodity become less important in the consumer's budget.

\subsection{Laspeyres Price Index Method}

Let $P_{i 0}$ and $q_{i 0}$ denote the price and quantity of the $i^{\text {th }}$ commodity in the base period 0 . Let $p_{i 0} q_{i 0}$ be the expenditures on the $\mathrm{i}^{\text {th }}$ commodity in base period. Let 
$p_{i 0} q_{i t}$ be the consumption of the $\mathrm{i}^{\text {th }}$ commodity in the current period. Then assume the regression of $p_{i 1} q_{i t}$ on $p_{i 0} q_{i t}$.

$$
p_{i t} q_{i 0}=\gamma_{t} p_{i 0} q_{i 0}+\varepsilon_{i t}, \mathrm{i}=1,2,3, \ldots, \mathrm{n}
$$

Here the constant $\gamma_{t}$ is a constant over the commodities and it measures the rate of inflation over all commodities. Here $\gamma_{t}$ varies with time. Let us impose the assumptions $\mathrm{E}\left(\varepsilon_{i t}\right)=0$ and $\operatorname{cov}\left(\varepsilon_{i t}, \varepsilon_{j t}\right)=\sigma_{t}^{2} p_{i 0} q_{i 0} \delta_{i j}, \delta_{i j}$ denote the kronecker delta on Eq.(2.10). In other words variability of disturbances falls as expenditures on commodities in the base period falls and vice versa. To find an estimator of $\gamma_{t}$ by resolving heteroscedasticity problem, Selvanathan and Selvanathan (2006) applied GLS to Eq.(2.10) and get the estimator of $\gamma_{t}$ below.

$$
\hat{\gamma}_{t}=\frac{\sum_{i=1}^{n} p_{i t} q_{i 0}}{\sum_{i=1}^{n} p_{i 0} q_{i 0}} \text { or } \quad \hat{\gamma}_{t}=\sum_{i=1}^{n} w_{i 0} \frac{p_{i t}}{p_{i 0}}
$$

Here $w_{i 0}=\frac{p_{i 0} q_{i 0}}{\sum_{i=1}^{n} p_{i 0} q_{i 0}}$ are the budget shares of $\mathrm{i}^{\text {th }}$ commodity in the base period and $\sum_{i=1}^{n} p_{i 0} q_{i 0}$ are the total expenditures in the period 0. Eq. (2.11) is a Laspeyres index which represents the relative prices of various commodities of buying the base period quantities in the current period. The advantage of Laspeyres index formula is that the budget share weights remain unchanged and only information on prices need to be obtained. However, it has some limitations that the index obtained by this formula gets inflated as the distance between base period and current period is large.

If we subtract one from Laspeyres index, it becomes equal to Divisia index. That is $\hat{\gamma}_{t}-1 \approx \sum_{i=1}^{n} \bar{w}_{i 0} D p^{0}{ }_{i t}=\hat{\alpha}_{t}$. The Divisia index and the Laspeyres index are approximately equal when base period and current period are close to each other. The variance of $\hat{\gamma}_{t}$ according to Selvanathan and Sevanathan (2006) is $\operatorname{var}\left(\hat{\gamma}_{t}\right)=\frac{\sigma_{t}^{2}}{\sum_{i=1}^{n} x_{i t}{ }^{2}}, \sigma_{t}^{2}$ 's and its unbiased estimator is $\hat{\sigma}_{t}^{2}=\frac{\sum_{i=1}^{n}\left(y_{i t}-\hat{\gamma}_{t} x_{i 0}\right)^{2}}{n-1} \quad$ which implies

$$
\operatorname{var}\left(\hat{\gamma}_{t}\right)=\frac{1}{n-1} \sum_{i=1}^{n} w_{i 0}\left(\frac{p_{i t}}{p_{i 0}}-\hat{\gamma}_{t}\right)^{2}
$$


Variance of Laspeyres index increases as the relative prices of the commodities increase. When the prices of individual commodities move away the over all index (rate of inflation) is not precise. Now Eq. (2.12) can be written as

$$
\operatorname{var}\left(\hat{\gamma}_{t}\right)=\frac{1}{n-1} \sum_{i=1}^{n} w_{i 0}\left(\frac{p_{i t}}{p_{i 0}}-1-\hat{\gamma}_{t}+1\right) \text { or } \operatorname{var}\left(\hat{\gamma}_{t}\right)=\frac{1}{n-1} \psi_{t}, \psi_{t}=\sum_{i=1}^{n} w_{i 0}\left(D p_{i t}^{0}-\hat{\alpha}_{t}\right)^{2}
$$

$\psi_{t}$ is equal to $\varphi_{t}$ which is Divisia second order weighted moment about mean. So variance of the rate of inflation is similar to Divisia second order weighted moment about mean multiplied by $1 /(n-1)$. Eq.(2.13) measures the degree of dispersion of relative prices \& by Divisia index we also get the same measure.

\section{An empirical illustration}

We have used monthly data on CPI for the period July 2001 to March 2008 for Pakistan obtained from Federal Bureau of Statistics monthly Bulletin of Statistics. The details of the data are as follows. The number of commodity classifications is 10 namely: Food and Beverages, Apparel Textile and Foot Wear, House Rent, Fuel and Lighting, House Hold Furniture and Equipment, Transport and Communication, Recreation and Entertainment, Education, Cleaning Laundry and Personal appearance, and Medicare. Full detail of the data is given in table 1.

Table 1: CPI Commodity Groups: log changes \& budget shares Pakistan

\begin{tabular}{lcr}
\hline \hline Commodity Groups & $\begin{array}{c}\text { CPI mean Log } \\
\text { Change *100 }\end{array}$ & $\begin{array}{r}\text { Weights= } \\
\mathbf{w}_{\mathbf{i}}^{*} \mathbf{1 0 0}\end{array}$ \\
\hline \hline Food and Beverages & 0.8157 & 39.8582 \\
Apparel Textile and Foot Wear & 0.3293 & 6.0977 \\
House Rent & 0.5441 & 23.4298 \\
Fuel and Lighting & 0.8603 & 7.2912 \\
House Hold Furniture and Equipment & 0.1927 & 3.2862 \\
Transport and Communication & 0.0796 & 7.3222 \\
Recreation and entertainment & -0.189 & 0.8259 \\
Education, & -0.028 & 3.4548 \\
Cleaning Laundry and Personal & 1.4033 & 5.8788 \\
appearance & & 2.0728 \\
Medicare. & 0.4251 & \\
\hline \hline
\end{tabular}


Table 2: Estimates of Rate of Inflation by Extended S.A., Laspeyres Index and their Standard Errors: Pakistan, July 2001 to March 2008.

\begin{tabular}{|c|c|c|c|c|c|c|}
\hline Time & $\alpha^{\star} 100$ & S.E $(\alpha)^{\star} 100$ & T-value & $Y^{*} 100$ & S.E $(Y)^{\star} 100$ & $\begin{array}{c}\text { Official } \\
\text { Inflation Rate }\end{array}$ \\
\hline Aug-01 & 1.29854 & 0.4283 & $9.587542^{* * *}$ & 1.3173 & 0.0483 & 0.7442 \\
\hline Sep-01 & -0.06795 & 0.1669 & -1.28746 & -0.0699 & 0.0433 & 0.1365 \\
\hline Oct-01 & 0.40740 & 0.1256 & $10.25726^{\star \star *}$ & 0.4163 & 0.0610 & 0.4860 \\
\hline Nov-01 & 0.08668 & 0.3818 & 0.717931 & 0.0914 & 0.0694 & 0.2808 \\
\hline Dec-01 & -0.52732 & 0.3104 & $-5.3722^{\star * *}$ & -0.5353 & 0.0511 & -0.4652 \\
\hline Jan-02 & 0.58694 & 0.0941 & $19.72441^{* \star \star}$ & 0.5933 & 0.0609 & 0.1068 \\
\hline Feb-02 & 0.33801 & 0.0949 & $11.26324^{\star \star \star}$ & 0.3390 & 0.0619 & 0.3197 \\
\hline Mar-02 & 0.92293 & 0.9614 & $3.035741^{* \star *}$ & 0.9656 & 0.1156 & 1.2973 \\
\hline Apr-02 & -0.24480 & 0.2597 & $-2.98085^{\star \star *}$ & -0.2503 & 0.1095 & 0.3431 \\
\hline May-02 & -0.09962 & 0.3004 & -1.04869 & -0.0979 & 0.1116 & -0.6683 \\
\hline Jun-02 & 0.89086 & 0.2244 & $12.55413^{\star \star \star}$ & 0.8991 & 0.1162 & 0.4778 \\
\hline Jul-02 & 0.90658 & 0.3986 & $7.192317^{* \star *}$ & 0.9302 & 0.1349 & 1.0809 \\
\hline Aug-02 & 0.22034 & 0.2053 & $3.393942^{* * *}$ & 0.2310 & 0.1444 & 0.3107 \\
\hline Sep-02 & 0.10954 & 0.0993 & $3.488378^{\star \star \star}$ & 0.1160 & 0.1500 & 0.1878 \\
\hline Oct-02 & 0.18893 & 0.2511 & $2.379327^{\star \star \star}$ & 0.1889 & 0.1509 & 0.1594 \\
\hline Nov-02 & 0.45994 & 0.1728 & $8.417002^{* \star *}$ & 0.4844 & 0.1707 & -0.0844 \\
\hline Dec-02 & 0.13708 & 0.3533 & 1.22696 & 0.1579 & 0.1878 & -0.2441 \\
\hline Jan-03 & 1.09096 & 0.3950 & $8.733971^{* * *}$ & 1.1252 & 0.2063 & 0.1597 \\
\hline Feb-03 & 0.37902 & 0.2243 & $5.343587^{\star \star *}$ & 0.4055 & 0.2222 & 0.4681 \\
\hline Mar-03 & -0.21310 & 0.3623 & -1.86001 & -0.2331 & 0.2093 & 0.0280 \\
\hline Apr-03 & -0.18025 & 0.4473 & -1.27431 & -0.1902 & 0.2024 & 0.3356 \\
\hline May-03 & 0.18289 & 0.2467 & $2.344341^{\star \star \star}$ & 0.1810 & 0.2009 & -0.2889 \\
\hline Jun-03 & -0.18893 & 0.2004 & $-2.98128^{* * *}$ & -0.1771 & 0.2075 & -0.2055 \\
\hline Jul-03 & 0.55818 & 0.2449 & $7.207514^{\star \star \star}$ & 0.5744 & 0.2166 & 0.5689 \\
\hline Aug-03 & 0.67440 & 0.1197 & $17.81654^{\star \star \star}$ & 0.7057 & 0.2347 & 0.6581 \\
\hline Sep-03 & 0.36734 & 0.3058 & $3.798663^{\star \star \star}$ & 0.4020 & 0.2528 & 0.5987 \\
\hline Oct-03 & 1.20603 & 0.3392 & $11.24352^{\star \star \star}$ & 1.2868 & 0.2897 & 1.4587 \\
\hline Nov-03 & 0.66288 & 0.0596 & $35.17132^{* \star *}$ & 0.6950 & 0.3050 & 0.5956 \\
\hline Dec-03 & 1.52256 & 0.3809 & $12.64048^{* * *}$ & 1.6281 & 0.3482 & 0.8957 \\
\hline Jan-04 & -0.01064 & 0.3054 & -0.11017 & -0.0024 & 0.3528 & -0.0892 \\
\hline Feb-04 & -0.03507 & 0.3470 & -0.3196 & -0.0710 & 0.3367 & -0.3397 \\
\hline Mar-04 & 1.14631 & 0.4731 & $7.662123^{* * *}$ & 1.1940 & 0.3550 & 1.0157 \\
\hline Apr-04 & -0.19970 & 0.4236 & -1.49081 & -0.1989 & 0.3549 & 0.9528 \\
\hline May-04 & 1.06040 & 0.7558 & $4.436728^{\star * \star}$ & 1.0769 & 0.3606 & 0.6913 \\
\hline
\end{tabular}




\begin{tabular}{|c|c|c|c|c|c|c|}
\hline Time & $\alpha^{\star} 100$ & S.E $(\alpha)^{*} 100$ & T-value & $Y^{\star} 100$ & S.E $(Y)^{*} 100$ & $\begin{array}{c}\text { Official } \\
\text { Inflation Rate }\end{array}$ \\
\hline Jun-04 & 0.85032 & 0.1264 & $21.27332^{\star \star \star}$ & 0.8927 & 0.3779 & 1.1100 \\
\hline Jul-04 & 1.28971 & 0.4273 & $9.544632^{\star \star \star}$ & 1.3939 & 0.4173 & 1.3704 \\
\hline Aug-04 & 0.59764 & 0.2662 & $7.099563^{\star \star \star}$ & 0.5885 & 0.4162 & 0.5768 \\
\hline Sep-04 & 0.34740 & 0.2600 & $4.225289^{\star \star \star}$ & 0.3453 & 0.4166 & 0.3799 \\
\hline Oct-04 & 1.02703 & 0.3061 & $10.61011^{\star \star *}$ & 1.0783 & 0.4355 & 1.1810 \\
\hline Nov-04 & 1.20508 & 0.1404 & $27.14243^{\star \star \star}$ & 1.2666 & 0.4593 & 1.1096 \\
\hline Dec-04 & 0.30176 & 0.3307 & $2.885543^{\star \star \star}$ & 0.3085 & 0.4639 & -0.8518 \\
\hline Jan-05 & 0.22661 & 0.3826 & $1.872984^{* *}$ & 0.2011 & 0.4538 & 0.9670 \\
\hline Feb-05 & 0.90547 & 0.5792 & $4.943625^{\star \star \star}$ & 0.9482 & 0.4739 & 0.9822 \\
\hline Mar-05 & 0.74807 & 0.1891 & $12.50981^{* \star *}$ & 0.7782 & 0.4859 & 1.2867 \\
\hline Apr-05 & 0.32132 & 0.5284 & $1.922981^{* *}$ & 0.2706 & 0.4658 & 1.7218 \\
\hline May-05 & -0.10653 & 0.3127 & -1.07732 & -0.1470 & 0.4494 & -0.4436 \\
\hline Jun-05 & 0.30335 & 0.1720 & $5.577191^{* * *}$ & 0.3011 & 0.4488 & 0.0952 \\
\hline Jul-05 & 1.27897 & 0.3286 & $12.30815^{\star * \star}$ & 1.3798 & 0.4875 & 1.6049 \\
\hline Aug-05 & 0.08826 & 0.3598 & 0.775716 & 0.0976 & 0.4928 & 0.0390 \\
\hline Sep-05 & 0.27727 & 0.2983 & $2.939339^{\star \star \star}$ & 0.3128 & 0.5084 & 0.4981 \\
\hline Oct-05 & 0.79800 & 0.2976 & $8.479495^{\star \star *}$ & 0.8517 & 0.5299 & 0.9349 \\
\hline Nov-05 & 0.82247 & 0.2062 & $12.61338^{\star \star \star}$ & 0.8506 & 0.5396 & 0.7585 \\
\hline Dec-05 & 0.60155 & 0.7146 & $2.662004^{\star \star \star}$ & 0.7193 & 0.5872 & -0.2751 \\
\hline Jan-06 & 1.23424 & 0.8789 & $4.440789^{\star * *}$ & 1.4586 & 0.6707 & 1.1944 \\
\hline Feb-06 & 0.67950 & 0.2379 & $9.032231^{* * *}$ & 0.7992 & 0.7136 & 0.3247 \\
\hline Mar-06 & 0.12514 & 0.2464 & 1.606037 & 0.0658 & 0.6936 & 0.2334 \\
\hline Apr-06 & 0.91199 & 0.3453 & $8.352058^{\star \star \star}$ & 0.9940 & 0.7251 & 1.0176 \\
\hline May-06 & 1.43830 & 1.1869 & $3.832087^{* * *}$ & 1.9572 & 0.9081 & 0.4531 \\
\hline Jun-06 & -0.36935 & 1.1062 & -1.05586 & -0.7600 & 0.7662 & 0.5837 \\
\hline Jul-06 & 1.56521 & 0.5259 & $9.41173^{* * *}$ & 1.8647 & 0.8649 & 1.5934 \\
\hline Aug-06 & 1.39720 & 0.3323 & $13.29622^{\star \star *}$ & 1.4992 & 0.8964 & 1.2395 \\
\hline Sep-06 & 0.01430 & 0.3955 & 0.114338 & -0.0636 & 0.8703 & 0.3146 \\
\hline Oct-06 & -0.15702 & 0.4503 & -1.10269 & -0.3022 & 0.8220 & 0.3563 \\
\hline Nov-06 & 0.57285 & 0.4662 & $3.885694^{* * *}$ & 0.6505 & 0.8496 & 0.7230 \\
\hline Dec-06 & 0.57514 & 0.1347 & $13.50224^{\star \star \star}$ & 0.6515 & 0.8763 & 0.4721 \\
\hline Jan-07 & 0.52667 & 0.2397 & $6.948172^{\star \star \star}$ & 0.5230 & 0.8772 & -0.8826 \\
\hline Feb-07 & 0.47019 & 0.6768 & $2.196914^{\star \star *}$ & 0.3606 & 0.8455 & 1.0301 \\
\hline Mar-07 & 0.73634 & 0.1889 & $12.32669^{\star \star \star}$ & 0.7500 & 0.8514 & 0.4901 \\
\hline Apr-07 & 0.90803 & 0.1776 & $16.16803^{\star \star *}$ & 0.9829 & 0.8777 & 0.3138 \\
\hline May-07 & 0.64930 & 0.2102 & $9.768158^{\star * *}$ & 0.6724 & 0.8837 & 0.9149 \\
\hline Jun-07 & 0.49392 & 0.2713 & $5.75714^{* * *}$ & 0.4526 & 0.8687 & 0.1999 \\
\hline Jul-07 & 1.10388 & 0.3583 & $9.742604^{\star \star \star}$ & 1.1323 & 0.8760 & 1.0071 \\
\hline
\end{tabular}




\begin{tabular}{|c|c|c|c|c|c|c|}
\hline Time & $\alpha^{*} 100$ & S.E $(\alpha)^{\star} 100$ & T-value & $Y^{*} 100$ & S.E $(Y)^{\star} 100$ & $\begin{array}{c}\text { Official } \\
\text { Inflation Rate }\end{array}$ \\
\hline Aug-07 & 1.38194 & 0.2013 & $21.70928^{* * *}$ & 1.4763 & 0.9084 & 1.3138 \\
\hline Sep-07 & 1.67359 & 0.3001 & $17.63531^{* * *}$ & 1.8319 & 0.9577 & 2.1037 \\
\hline Oct-07 & 1.20626 & 0.3871 & $9.854118^{\star \star \star}$ & 1.3974 & 1.0241 & 1.2179 \\
\hline Nov-07 & 1.58071 & 0.7211 & $6.93197^{\star * *}$ & 1.9766 & 1.1640 & 0.1366 \\
\hline Dec-07 & 1.73720 & 0.4737 & $11.59702^{* \star *}$ & 1.8661 & 1.1943 & 0.5832 \\
\hline Jan-08 & 3.03221 & 0.7089 & $13.52615^{\star \star \star}$ & 3.6039 & 1.3624 & 1.8945 \\
\hline Feb-08 & -0.91883 & 0.9571 & $-3.03583^{* * *}$ & -0.9414 & 1.3894 & 0.4870 \\
\hline Mar-08 & 3.13376 & 0.9549 & $10.37786^{* \star *}$ & 3.6335 & 1.5474 & 3.0324 \\
\hline Means & 0.64030 & 0.0499 & $12.8317^{\star \star \star}$ & 0.6894 & 0.0697 & 0.5974 \\
\hline
\end{tabular}

In table 2, we report the estimated rate of inflation in column 1 and in column 2 standard error for the rate of inflation is given and in column 3 corresponding tvalues are provided, expect few all the t-values suggest that rate of inflation is significantly different from zero. In column 4 of table 2 , we reported the rate of inflation estimated using Laspeyres index under stochastic approach to index numbers. In column 5 standard error of rate of inflation using Laspeyres index is given. The corresponding official rate of inflation calculated by FBS is given in last column of table. We compared our results to the published figure on rate of inflation. We find that the point estimate for mean monthly rate of inflation comes out to be $0.64030 \%$ by extended stochastic approach to index numbers which is weighted average of price log changes using Eq. (2.5). The point estimate $0.640 \%$ is close to the official rate of inflation $0.597 \%$, which is expected. Laspeyres index number estimate of rate of inflation by using Eq. (2.11) comes out $0.68 \%$ All three point estimates of rate of inflation are not very much different from each other. The standard error for the rate of inflation using Eq. (2.7) is $0.0499 \%$ which is Clements and Izan (1987) formula and using Eq. (2.21) is $0.052 \%$ which is Crompton (2000) formula and that of using Eq. (2.13) is $0.069 \%$ which is Laspeyres method, the difference may be due to heteroscedasticity. Heteroscedasticity present in our data is not of the same structure which was assumed by Clements and Izan (1987) because when we computed the residual variances (reported in Table 3) of individual commodities; it did not come out inversely proportional to the corresponding weights. We have also computed Crompton (2000) ${ }^{1}$ variance for the rate of inflation in this study. Almost $51 \%$ of the values of variance computed by using Crompton (2000) formula are smaller than those computed using Clements and Izan (1987) formula,

\footnotetext{
${ }^{1}$ It is robust to unknown forms of heteroscedasticity
} 
Table 3: $\quad$ Residual variances and weights of commodities

\begin{tabular}{lcr}
\hline \hline Commodity Groups & $\begin{array}{c}\text { Residual } \\
\text { variance*10000 }\end{array}$ & wi $^{*} \mathbf{1 0 0}$ \\
\hline \hline Food \& Beverages & 0.71763 & 40.3412 \\
Apparel, Textile \& Footwear & 0.77696 & 6.0977 \\
House Rent Index & 0.43096 & 23.4298 \\
Fuel and Lighting & 5.97328 & 7.2912 \\
House hold Furniture \& Equipment & 0.51475 & 3.2862 \\
Transport \& Communication & 0.71244 & 7.3222 \\
Recreation \& Entertainment & 2.98349 & 0.8259 \\
Education & 0.93195 & 3.4548 \\
Cleaning Laundry \& Personal & & \\
Appearances & 12.6998 & 5.8788 \\
Medicare & 1.31961 & 2.0728 \\
\hline \hline
\end{tabular}

In figure 1, scatter diagram of the estimate of rate of inflation is plotted against its corresponding standard error (Using Eq. (2.7)), solid line is the least square regression line. There is is a positive relationship between the rate of inflation and its standard error. In case of high inflation it is difficult to estimate it precisely in absolute sense i.e standard error of the rate of inflation tends to rise. However, the ratio of increase in the rate of inflation is higher than the increase in standard error.

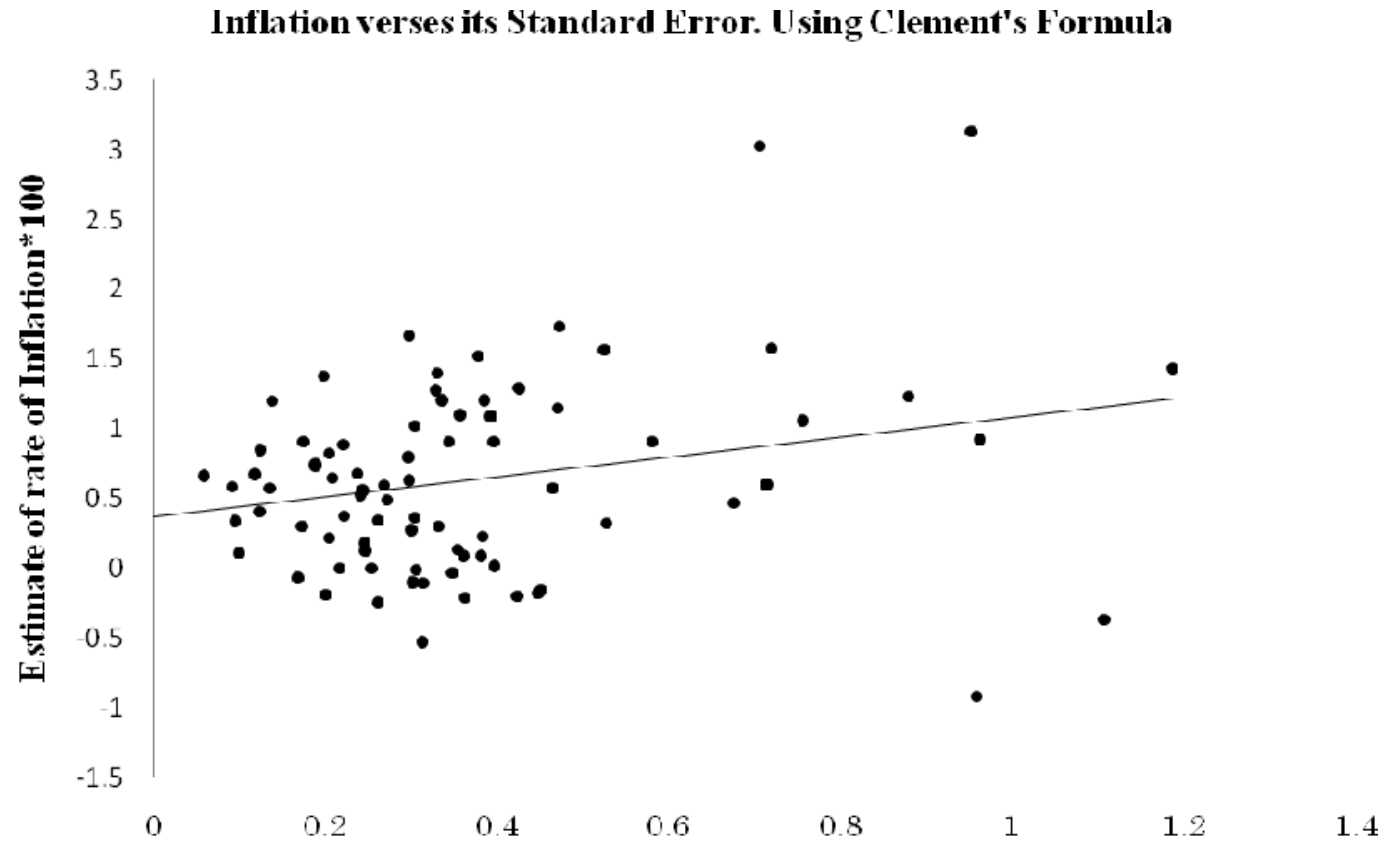

Figure 1. Standard error of inflation*100 
Figure 2, in which scatter diagram of estimate of inflation is plotted against its standard error, which confirms that precise measure of inflation is not possible when its standard error is higher. In Figure 3,95\% confidence band is constructed assuming the normal distribution $\hat{\alpha}_{t} \pm 1.96\left(\operatorname{var} \hat{\alpha}_{t}\right)^{1 / 2}$ for the estimated rate of inflation, using Clement and Izan (1987) formula. We assumed that prices are log normally distributed. According to Clements and Izan (1987; p345) "it is reasonable". Again in figure 4, 95\% confidence band for rate of inflation is plotted using Crompton (2000) formula; all the points lie in $95 \%$ confidence interval.

In figure 5, we plotted 95\% confidence band for the official rate of inflation. Except couple of points all points lie in the $95 \%$ confidence band. This suggest that stochastic approach estimates the rate of inflation which covers the official rate of inflation.

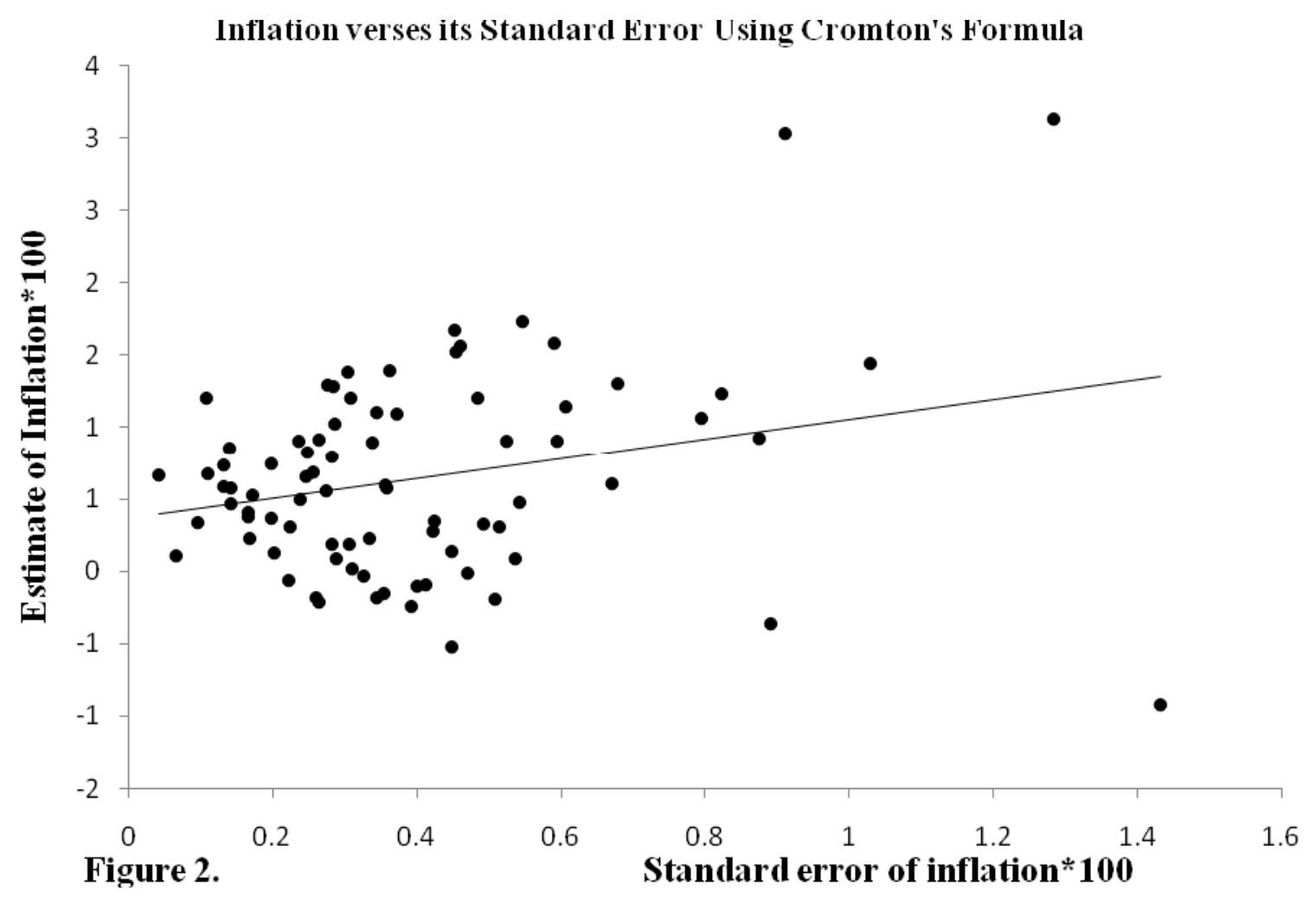




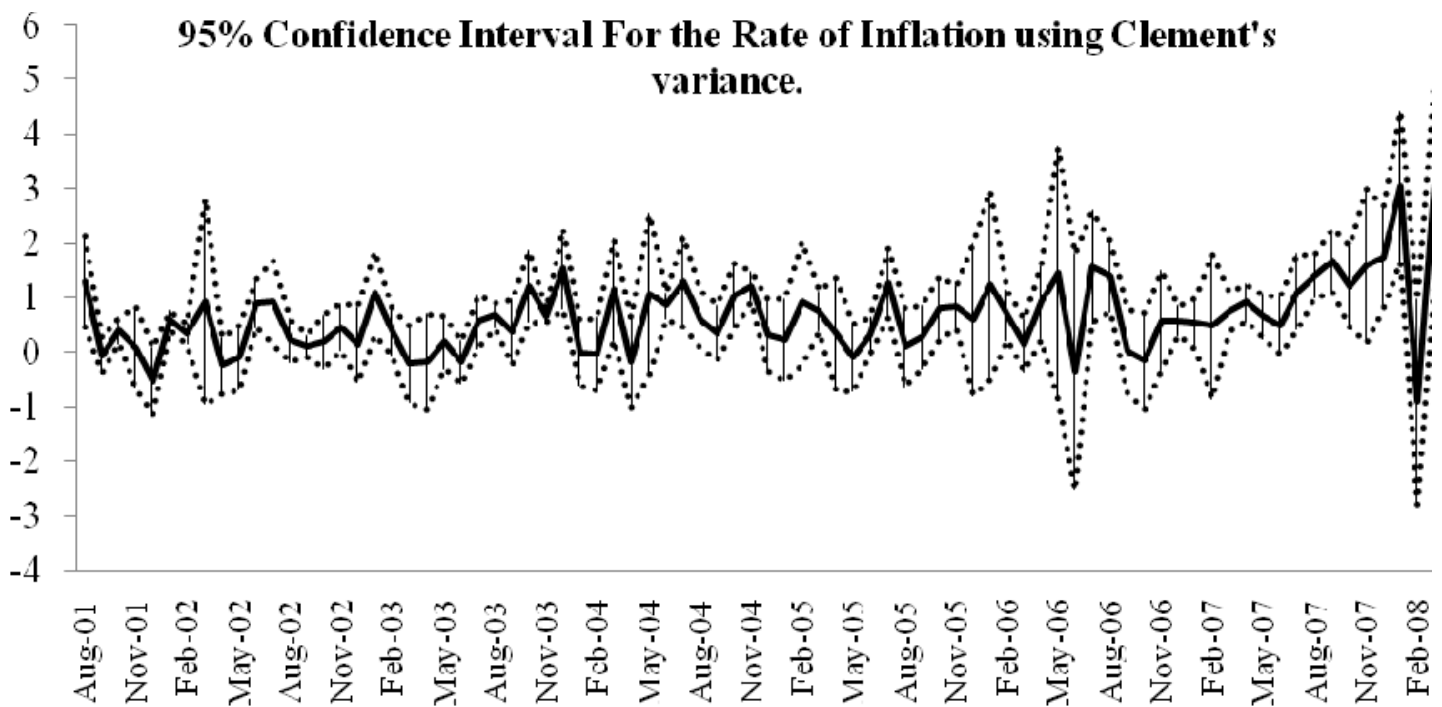
Figure 3 Years and Months

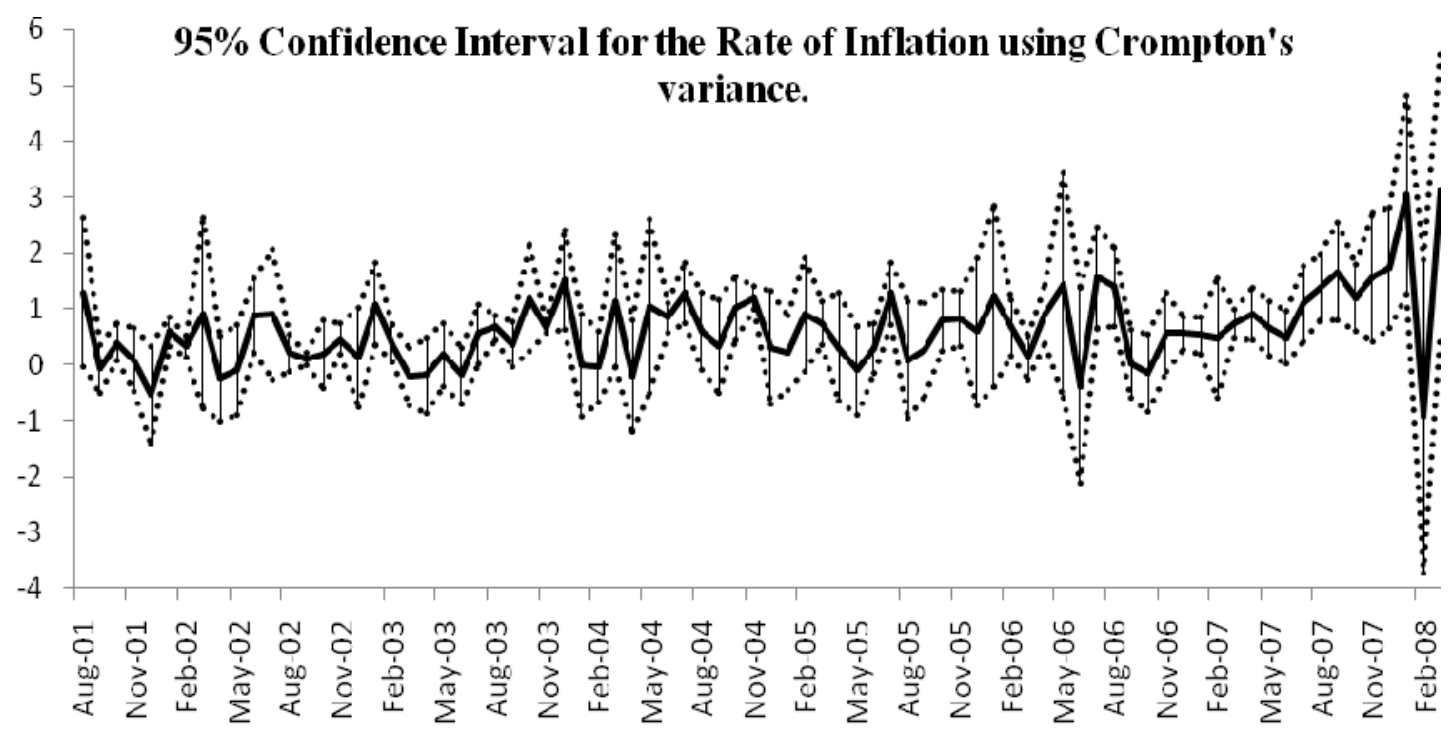

Figuge 4. Years and Months 


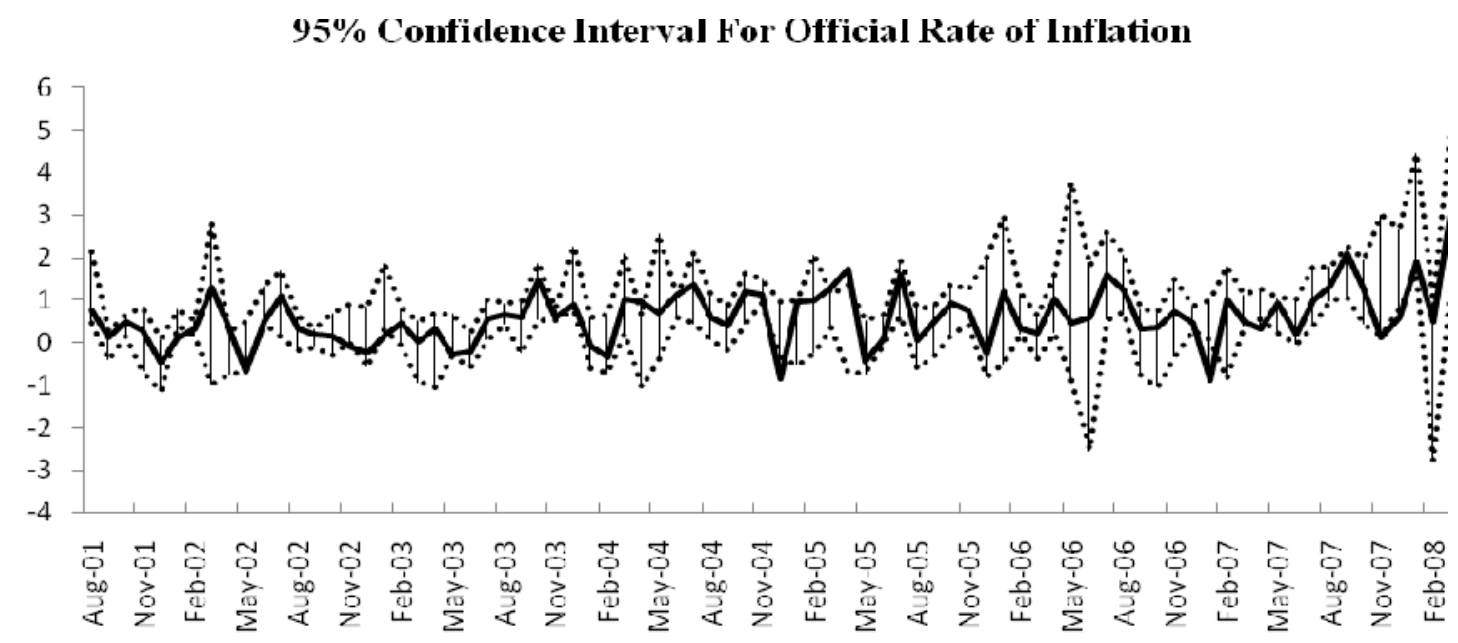

Figure 5

Years and Months

lower limit" 100

CPI log change'100

upper limit' 100

Table 4: Estimates of Relative Price Changes: Pakistan, Jul 2001-Mar 2008

\begin{tabular}{|c|c|c|c|}
\hline Commodity Groups & $\hat{\beta}_{i}$ & S.E of $\hat{\beta}_{i}$ & T-Value \\
\hline Food \& Beverages & 0.19273 & 0.02941 & $13.25218^{* * *}$ \\
\hline Apparel, Textile \& Footwear & -0.2287 & 0.0949 & -0.33417 \\
\hline House Rent Index & -0.11 & 0.04372 & $1.990688^{\star \star}$ \\
\hline Fuel and Lighting & 0.17681 & 0.08623 & $4.334916^{* * *}$ \\
\hline House hold Furniture \& Equipment & -0.5316 & 0.13119 & $-2.55043^{\star \star \star}$ \\
\hline Transport \& Communication & -0.521 & 0.08603 & $-3.76636^{\star * \star}$ \\
\hline Recreation \& Entertainment & -0.6145 & 0.26499 & -1.57543 \\
\hline $\begin{array}{l}\text { Education } \\
\text { Cleaning Laundry \& Personal }\end{array}$ & -0.6381 & 0.12783 & $-3.45101^{\star * \star}$ \\
\hline Appearance & 0.67028 & 0.09676 & $8.963107^{* \star \star}$ \\
\hline Medicare & -0.3668 & 0.16621 & -1.02151 \\
\hline
\end{tabular}

Table 4 shows that the relative price of food beverages is 0.19273 , an increase that is highly significant even at one percent level of significance with the t-value 13.25; the point estimate 0.19273 is more than six times its standard error. The estimated relative price of Apparel, Textile and Footwear is did not change significantly, with the t-value -.33 . The estimated relative price of house rent index decline with t-value 1.99. Next the estimated relative price of fuel and lighting increase by 0.1768 percent. This value is highly significant even at one percent. The estimated relative price of Household, Furniture and Equipment declines with the t-value -2.55 , which is significant at one percent. The estimated relative price of Transport and Communication also declines with t-value -3.76636 , which is significant at one percent. The estimated relative price of 
recreation and entertainment is almost constant. There is a decrease in relative price of education by -0.6381 which is significant at $5 \%$. At the end, the estimated relative price of cleaning laundry and personal appearance is increased in real terms by 0.67 , which is not ignorable. Medicare does not change considerably; as its estimated relative price is not significant even at $5 \%$.Our model pass all diagnostic tests. Autocorrelations up to lag 12 lags because we have monthly data are also computed and apply Durbin Watson test to check its significance. We find hardly any high correlation except for food and cleaning group which are 0.2 and 0.21 respectively.

\section{Table 5: Contemporaneous Residual Correlations}

\begin{tabular}{lrrrrrrrrr}
\hline \hline & Food & Appa. & Hous. & Fuel & HHol & Tran. & Recre. & Edc. & Clea. \\
\hline \hline Appa. & -0.4810 & & & & & & & & \\
Hous. & -0.6327 & 0.5985 & & & & & & & \\
Fuel & -0.4187 & -0.1296 & -0.0944 & & & & & & \\
HHol. & -0.5504 & 0.5646 & 0.7870 & -0.1383 & & & & & \\
Tran. & -0.5918 & 0.5552 & 0.7277 & 0.0280 & 0.6441 & & & & \\
Recre. & -0.1518 & 0.3749 & 0.2619 & -0.0711 & 0.3232 & 0.2885 & & & \\
Edc. & -0.3792 & 0.5439 & 0.5733 & -0.0899 & 0.6396 & 0.4186 & 0.3143 & & \\
Clea. & -0.3471 & -0.1867 & -0.2359 & -0.0370 & -0.1904 & -0.2214 & -0.2432 & -0.2939 & \\
Med. & -0.2890 & 0.4060 & 0.4237 & -0.0133 & 0.5002 & 0.2861 & 0.2044 & 0.4607 & -0.2740 \\
\hline \hline
\end{tabular}

The objective of this study is to find the confidence interval for the rate of inflation for Pakistan because in interval estimation we achieve some level of confidence that our estimated range will contain the true parameter on rate of inflation. To achieve this objective the methodology we used is stochastic approach to index numbers because this is the only approach which provides confidence interval for index numbers. We use monthly data on CPI for Pakistan to measure confidence interval of the rate of inflation. In the end we conclude that if price of individual commodities are widely dispersed then the level of uncertainty for measuring the rate of inflation will be very high. In such a case stochastic approach to measure inflation will both be effective and flexible in setting the inflation target in a range with certain level of confidence. Interval estimate is better than point estimate because in case of latter we have no knowledge whether this estimate will approach to underlying parameter or not. Standard errors computed through stochastic approach makes it possible to test the hypothesis about the index numbers. It is suggested that monetary policy authority should set inflation target in an interval rather than as a point estimate. We, therefore, suggest that it is better to use stochastic approach to index numbers besides calculating point estimate. Stochastic approach makes it possible to test the hypothesis about the index numbers. 


\section{References}

1. Balk, B. M. (1995). Axiomatic Price Index Theory: A Survey. International Statistical Review, 63: 69-93.

2. Casella, G. and R. L. Berger, (2002). Statistical Inference. Thomson Duxbury.

3. Clements, K. W. and H. Y. Izan, (1981). A Note on Estimating Divisia Index Numbers. International Economic Review, 22: 745-7.

4. Clements, K. W. and H. Y. Izan, (1985). Australian Consumer Price Data, 1952-1981. Discussion Paper 85.01, University of Western Australia, Department of Economics.

5. Clements, K. W. and H. Y. Izan, (1987). The Measurement of Inflation: A Stochastic Approach. Journal of Business and Economic Statistics, 5(3): 339-50.

6. Clements, K. W., Selvanathan, E. A. and H. Y. Izan, (2006). Stochastic Index Numbers: A Review.

7. Clements, K. W. and E. A. Selvanathan, (2007). More on Stochastic Index Numbers. Applied Economics Letters, 39:5, 605-611.

8. Crompton, P. (2000). Extending the Stochastic Approach to Index Numbers. Applied Economics Letters, 7: 367-71.

9. Diewert, W. E. (1981). The economic theory of index numbers in essays in the theory and measurement of consumer behavior (in honor of Richard Stone) (ED). A. Deaton, Cambridge University Press, N.Y., pp 163-208.

10. Diewert, W. E. (1995). On the Stochastic Approach to Index Numbers. Discussion paper No. 95-31, Department of Economics, University of British Columbia.

11. Diewert, W. E. (2007). Index Numbers. The New Palgrave Dictionary of Economics.

12. Fisher, I. (1922). The Making of Index Numbers. Boston: Houghton Muffin.

13. Frisch, R. (1936). Annual Survey of General Economic Theory: The Problem of Index Numbers. Econometrica, 4, 1-38.

14. Selvanathan, E. A. (1989). A Note on the Stochastic Approach to Index Numbers. Journal of Business and Economic Statistics, 7: 471-74.

15. Selvanathan, E. A. (2003). Extending the stochastic Approach to Index Numbers. A Comment. Applied Economics Letters, 10 (4): 213-215.

16. Selvanathan, E. A. and S. Selvanathan, (2003). International Consumption Comparisons: OECD vs. LDC. Singapore, New York: World Scientific Publishers.

17. Selvanathan, E. A. and S. Selvanathan, (2004). Modeling the Commodity Prices in the OECD Countries: A Stochastic Approach. Economic Modeling, 21(2): 233-247.

18. Selvanathan, E. A. and S. Selvanathan, (2006). Recent Developments in the Stochastic Approach to Index Numbers. Applied Economics, Taylor and Francis Journals, vol. 38(12), pages 1353-1362.

19. Theil, H. (1975). Theory and Measurement of Consumer Demand, (Vol. 1) Amsterdam: North- Holland.

20. Wilson, G. G. (1982). Inflation: Causes, Consequences, and Cures. Indiana University Press Bloomington. 